\title{
Health and Environmental Impact of Pesticide Application In-and-Around Cocoa Storage Facilities in Ghana
}

\author{
W. Azalekor ${ }^{1,2, *}$, J.V.K. Afun², , E.A. Osekre², E.A. Oyewo ${ }^{2}$ \\ ${ }^{1}$ Research Department of Quality Control Company, Ghana Cocoa Board. Box Co 247, Tema, Ghana. \\ ${ }^{2}$ Soil and Crop Science Department, Kwame Nkrumah University of Science and Technology, Kumasi, Ghana.
}

\section{A R T I C L E D E T A I L S}

Article history:

Received 21 March 2019

Accepted 18 April 2019

Available online 06 May 2019

\section{Keywords:}

Pesticide Applicators

PPE

Cypermethrin

Disinfestation

\begin{abstract}
A B S T R A C T
Direct and indirect contamination of humans and animals and the environment by pesticides discharged into the environment is a serious health risk resulting in chronic toxicity. The health and environmental impact of pesticide application in and around some cocoa storage facilities was studied by eliciting information from workers of COCOBOD, who work regularly in the storage facilities, and other people who live around the storage facilities, using questionnaires. Additionally, wall paint and soil samples were taken from the storage environment and the level of contamination determined. The results of the study showed that majority of the people who work in the cocoa storage environment have formal education up to secondary and tertiary levels, but most of the pesticide applicators ignore the usage of full complement of PPE, especially full-face mask. The pesticide applicators (QCC disinfestation staff) listed headache, sneezing, sweating, numbness of fingers, tiredness and runny nose after application of pesticide, as some of the toxicity symptoms noticed after application of the pesticides. Soil around QCC treatment facility and the wall paint of the facility were found to be contaminated with insecticides far above their MRLs in cocoa. It is instructive to indicate that Cypermethrin that was last used in the cocoa storage environment in 2015, three years before the test, was also detected in the soil and wall paint.
\end{abstract}

\section{Introduction}

Pesticides are used to enhance and stabilise crop yield, protect the nutritional integrity of food, facilitate storage to assure year-round supplies, and provide attractive and appealing food products devoid of pests and consequences of their activities. The proper use of pesticides is beneficial to public health and to the protection of crops from pest and contamination by natural toxins produced by harmful microorganisms.

According to Okori et al. [1] without pesticides food would be more expensive because its production would require more labour in order to manage pests and diseases. However, pest control policy, especially in developing countries has largely been dependent upon the use of synthetic pesticides [2]. Pesticides are toxic in nature and do not differentiate between target and non-target species of plants and animals, and therefore the need to use them judiciously, since their injudicious use may lead to accidents, residual poisoning of foods, fruits, vegetables, and environment and even in mother's milk, and this has become a matter of great concern [3].

Persistent pesticides are highly toxic, causing an array of adverse effects, notably, diseases, birth defects among human and animals and sometimes death. It is estimated that about 355,000 people die globally each year due to unintentional acute poisonings [4], of which two-thirds occur in developing countries mainly due to excessive exposure and or inappropriate use in occupational and domestic environments [5, 6]. Longterm, low-dose exposure of pesticides causes chronic human poisoning [7, 8 , 9]. When applied, most of the pesticides remain as 'residue' in the environment and enter the terrestrial and aquatic food chains where they undergo concentration and exert, long term, adverse health effects [10, 11].

Farmers, pesticide applicators and populations near agricultural areas where pesticides are heavily used are particularly prone to adverse health effects due to their direct/indirect exposure to the pesticides $[12,13]$. Under field conditions, successive multiple sprays, fogging and fumigation with various insecticides during the storage of produce jeopardise the health of nearby communities [14], therefore the need for this study.

*Corresponding Author:wewinky2001@yahoo.com(William Azalekor)

\section{Experimental Methods}

The impact of pesticides being used in the cocoa storage environment on the people and the environment was assessed by administering questionnaires to elicit information from respondents while samples of wall paint and soil around storage facilities were taken to determine the contamination of the environment.

\subsection{Administration of Questionnaire}

A four-part semi-structured questionnaire was developed and used to elicit information from pesticide handlers (pest controllers) from Quality Control Company (QCC) of Ghana Cocoa Board (COCOBOD), workers of Licensed Buying Companies (LBCs)/Cocoa Marketing Company (CMC), COCOBOD handlers of cocoa storage facility and people living in the vicinity of cocoa storage facilities. In all 100 questionnaires were administered on the respondents using one-on-one method of questionnaire administration. The purposive sampling approach was used. One week before data collection started, the questionnaire was pretested on 10 staff each from QCC and CMC at Tema Take Over Centre (TOC). Major questions in the questionnaire covered areas bordering on gender, age, educational level, occupation of the participants, frequency of pesticide application, use of protective clothing, knowledge and adherence to basic rules on pesticide application, effectiveness of pesticide use as pest control strategy and ailments experienced that can be attributed to exposure to pesticides

\subsection{Evaluation of Levels of Pesticide Residues}

In order to ascertain the level of residues of the active ingredients of the various pesticides being used to control pests in cocoa storage environments, three samples of wall paint were collected from various spots of the five storage facilities, while three soil samples each were collected at spots $5 \mathrm{~m}$ and $10 \mathrm{~m}$ away from the facilities. The wall paint and soil samples were taken to the Pesticide Residue Analysis Laboratory to determine the level of pesticide residues in them, using the multi-residue method for agricultural chemicals by GC/MS and LC/MS/MS (agricultural products) [15]. 


\subsection{Data Analysis}

The completed questionnaires were cleaned and some information verified. The responses were then entered into a pre-coded SPSS template. Data were analysed using the IBM SPSS Statistics (20), microsoft excel and chi square (to measure significance and dependence between variables).

\section{Results and Discussion}

\subsection{Socio-Economic Background of Respondents}

There were 100 respondents with 77 of them being males. There was QCC staff dominance (38) of respondents as they were the group that use pesticide most and therefore usually exposed to pesticides. Respondents from LBCs and those who live around the cocoa storage structures were 23 each, while respondents from CMC were 16.

The ages of respondents ranged from 18 to 60 years with modal and mean ages being 45.5 and 35.5 years, respectively (Table 1). About $86 \%$ of the respondents were within the high productivity working age group of 18-50 years. A large proportion (98\%) of the respondents had formal education; out of which $71 \%$ had secondary to tertiary education, suggesting that majority of the respondents were well educated and must be knowledgeable enough to appreciate the health effects of pesticide application (Table1)

Table 1 Biodata of Respondents to questionnaire on health and environmental impact of pesticide application on people associated with cocoa storage facilities

\begin{tabular}{|c|c|c|c|c|c|c|c|}
\hline \multirow{3}{*}{\multicolumn{2}{|c|}{$\begin{array}{l}\text { Characteristics of } \\
\text { respondents }\end{array}$}} & \multicolumn{6}{|c|}{ Respondents } \\
\hline & & \multicolumn{2}{|c|}{ Males } & \multicolumn{2}{|c|}{ Females } & \multicolumn{2}{|l|}{ Total } \\
\hline & & Freq. & $\%$ & Freq. & $\%$ & Freq. & $\%$ \\
\hline & $18-25$ & 7 & 9.0 & 4 & 17.4 & 11 & 11 \\
\hline & $26-30$ & 11 & 14.0 & 6 & 26.1 & 17 & 17 \\
\hline \multirow[t]{3}{*}{ Age group } & $31-40$ & 35 & 45.5 & 6 & 26.1 & 41 & 41 \\
\hline & $41-50$ & 15 & 19.5 & 4 & 17.4 & 19 & 19 \\
\hline & $51-60$ & 9 & 12.0 & 3 & 13.0 & 12 & 12 \\
\hline \multicolumn{2}{|l|}{ Total } & 77 & 100.0 & 23 & 100.0 & 100 & 100.0 \\
\hline \multicolumn{8}{|c|}{ Educational Background } \\
\hline \multicolumn{2}{|c|}{ Formal Education } & 2 & 3 & 0 & 0 & 2 & 2 \\
\hline \multicolumn{2}{|c|}{ Basic Education } & 21 & 27 & 6 & 26 & 27 & 27 \\
\hline \multicolumn{2}{|c|}{ Secondary/Technical } & 37 & 48 & 9 & 39 & 46 & 46 \\
\hline \multicolumn{2}{|c|}{ Tertiary Education } & 17 & 22 & 8 & 35 & 25 & 25 \\
\hline \multicolumn{2}{|l|}{ Total } & 77 & 100 & 23 & 100 & 100 & 100 \\
\hline \multicolumn{8}{|l|}{ Occupation } \\
\hline \multicolumn{2}{|l|}{ QCC } & 31 & 40 & 7 & 30.4 & 38 & 38 \\
\hline \multicolumn{2}{|l|}{$\mathrm{CMC}$} & 12 & 16 & 4 & 17.4 & 16 & 16 \\
\hline \multicolumn{2}{|l|}{ LBCs } & 18 & 23 & 5 & 21.7 & 23 & 23 \\
\hline \multicolumn{2}{|l|}{ Others } & 16 & 21 & 7 & 30.4 & 23 & 23 \\
\hline \multicolumn{2}{|l|}{ Total } & 77 & 100 & 23 & 100 & 100 & 100 \\
\hline
\end{tabular}

\subsection{Frequency and Effectiveness of Existing Pest Control Practices}

Responses from the survey showed that the storage facility was usually sprayed at the beginning of the season before the cocoa was put into the facility. Forty-five per cent of the respondents indicated this pre-storage spray was applied only once in the season (Table 2).

Table 2 Frequency of insecticide application in Cocoa storage environments, Suhum District; 2016 and 2017 crop years

\begin{tabular}{llll}
\hline Spraying Frequency & Respondents (\%) & Fogging Frequency & Respondents (\%) \\
\hline Once/Season & 45.0 & Once/Week & 5 \\
Twice/Season & 10.0 & Twice/Week & 20 \\
Thrice/Season & 28.0 & Thrice/Week & 67 \\
Four times/Season & 27.0 & Four times/Week & 8 \\
Total & 100.0 & Total & 100 \\
\hline
\end{tabular}

Number of respondents $=100$

Table 3 Number of years current pest control regimen has been practised and its effectiveness thereof

\begin{tabular}{llll}
\hline $\begin{array}{l}\text { Number of years } \\
\text { practised }\end{array}$ & $\begin{array}{l}\text { Respondents } \\
(\%)\end{array}$ & $\begin{array}{l}\text { Effectiveness of } \\
\text { Practice }\end{array}$ & $\begin{array}{l}\text { Respondents } \\
(\%)\end{array}$ \\
\hline Five years & 4 & Not effective & 21 \\
Ten years & 19 & Fairly effective & 9 \\
Fifteen years & 26 & Good & 12 \\
More than fifteen years & 46 & Very good & 36 \\
Don't know & 5 & Excellent & 22 \\
Total & 100 & Total & 100 \\
\hline
\end{tabular}

Number of respondents $=100$
However, fogging was undertaken as and when necessary. Sixty-seven per cent indicated that fogging was done three times a week, until the cocoa was evacuated from the facility (Table 2). The study revealed that the current pest control regimen had persisted in the cocoa storage environment for more than fifteen years and had been very effective.

\subsection{Adherence to Standard Pest Control Procedures}

It was observed that, to a large extent, standard procedures for pest control were adhered to, as spraying was generally undertaken in the morning between 0800 and $1000 \mathrm{H}$ or in the evening between 1600 and $1700 \mathrm{H}$, according to $53 \%$ of the respondents. Eighty-nine per cent of the respondents indicated fogging was carried out in the evenings (1600 to $1700 \mathrm{H})$. The number of staff that formed a team for pest control operations ranged from 2 to 15 people (Fig. 1)

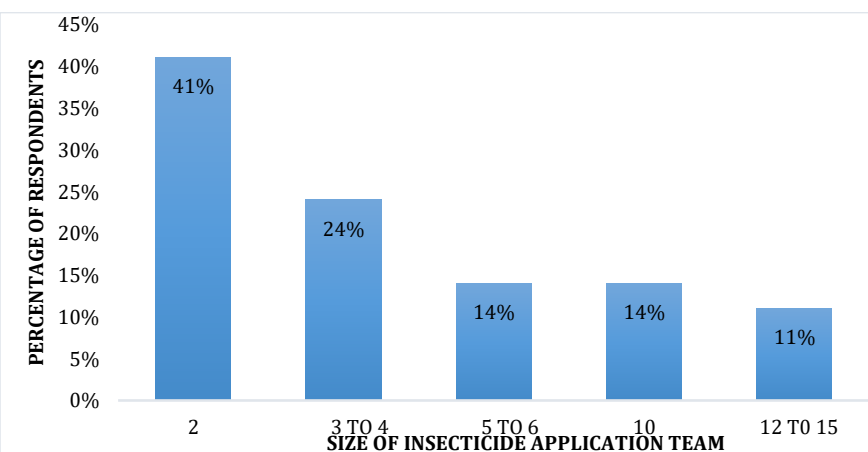

Fig. 1 Number of people in an insecticide application team

Pest control team members wore various combinations of personal protective equipment (PPE) as indicated in Fig. 2. Observations however, revealed that about a third of members of pest control teams were not fully geared with the right PPE mentioned. Facemask, gloves and safety boots were largely ignored, implying a large number of the QCC pest controllers were exposed to contamination by pesticides.

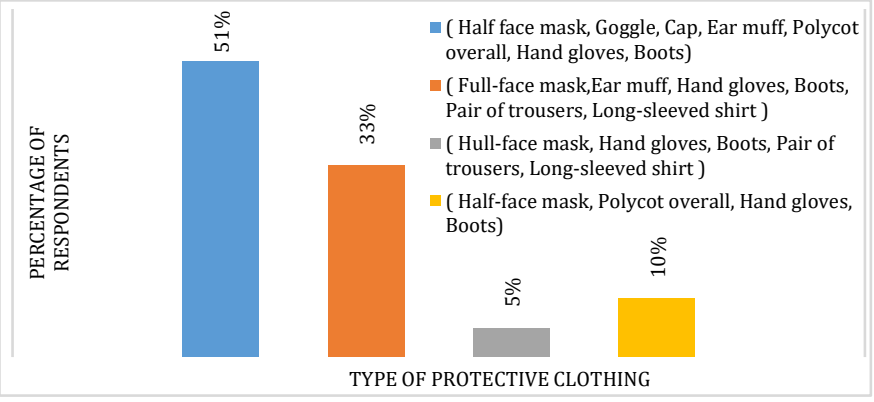

Fig. 2 Type of protective clothing used by pest control team members

According to respondents' tonnage capacities, volumes and the surface areas of the facilities involved were the main determinants of the quantity of pesticide to apply during spraying or fogging but $55 \%$ of the respondents indicated tonnage capacity of the storage structure is the approach frequently used (Fig. 3).

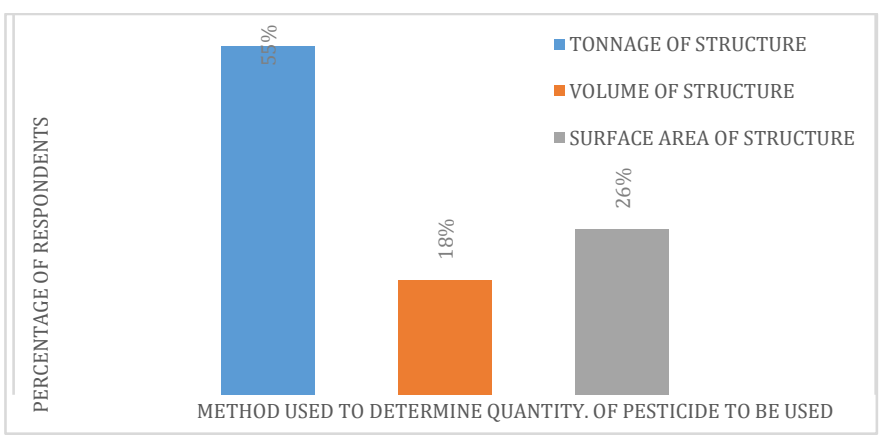

Fig. 3 Criteria used in determining the quantity of pesticide to be used in an operation

It came to light that only $43 \%$ of warehouse operators were informed of pending pest control operations in their warehouses and those informed received the message either by phone call $(77 \%)$ or by a letter. However, almost all respondents claimed they had had some education on the effect of exposure to pesticides through QCC (86\%) and NGOs (14\%). 
Eight two per cent of the respondents cover their consumables (food and water), 5\% take them away from the place of application for the fear of contamination while $13 \%$ leave them unattended to, during insecticide applications. The study also revealed that $72 \%$ of the people in and around the pesticide application area leave the place for at least 30 minutes to avoid exposure to the pesticide while the rest stay on unconcerned.

It was also found out that a large portion (67\%) of the respondents used empty pesticide containers to store oil and water, while only $20 \%$ destroyed the containers either by burying or burning them. The remaining $13 \%$ used them for various other purposes.

\subsection{Health Effects of Pesticide Application}

The major health effects experienced by pesticide applicators after application were as follows: headache (37\%), sneezing (34\%), sweating $(13 \%)$, numbness in the fingers $(11 \%)$, tiredness $(3 \%)$ and runny nose (3\%). Various adverse health complaints were reported by COCOBOD workers (QCC and CMC), and those who stay around the storage environment after every pest control operation in the storage environment. The complaints were associated more with occupation, as QCC workers reported the highest complaints (38\%) followed by LBCs (22\%) (Table 4). The complaints reported include bad odour, runny nose, headache, sneezing and drowsiness. Bad odour was the commonest complaint $(38 \%)$ followed by sneezing $(28 \%)$ and headache $(16 \%)$ (Table $5)$.

Table 4 Frequency of adverse health complaint after pesticide applications

\begin{tabular}{lllll}
\hline \multirow{2}{*}{$\begin{array}{llll}\text { Occupational } \\
\text { Group }\end{array}$} & Yesponse & NO & \\
QCC & Freq. & $\%$ & Freq. & $\%$ \\
CMC & 29 & 37.6 & 9 & 11.7 \\
LBC & 12 & 15.6 & 4 & 5.2 \\
TOTAL & 17 & 22.1 & 6 & 7.8 \\
\hline
\end{tabular}

$\chi^{2}$ value $=8.0212 ; d f=2 ; P<0.05$.

Table 5 Types of adverse health complaints reported

\begin{tabular}{|c|c|c|c|c|c|c|c|c|}
\hline \multirow{3}{*}{$\begin{array}{l}\text { Types of } \\
\text { Complaint }\end{array}$} & \multicolumn{8}{|c|}{ Response by Occupation } \\
\hline & \multicolumn{2}{|l|}{$\overline{\mathrm{QCC}}$} & \multicolumn{2}{|l|}{ CMC } & \multicolumn{2}{|l|}{ LBC,s } & \multicolumn{2}{|c|}{ TOTAL } \\
\hline & Freq. & $\%$ & Freq. & $\%$ & Freq. & $\%$ & Freq. & $\%$ \\
\hline Bad Odour & 9 & 15.5 & 4 & 6.9 & 9 & 15.5 & 22 & 37.9 \\
\hline Runny nose & 3 & 5.2 & 1 & 1.7 & 4 & 6.9 & 8 & 13.9 \\
\hline Sneezing & 8 & 13.8 & 5 & 8.6 & 3 & 5.2 & 16 & 27.6 \\
\hline Headache & 7 & 12.1 & 2 & 3.4 & 0 & 0 & 9 & 15.5 \\
\hline Drowsiness & 2 & 3.4 & 0 & 0 & 1 & 1.7 & 3 & 5.2 \\
\hline Total & 29 & 50 & 12 & 20.6 & 17 & 29.3 & 58 & 100 \\
\hline
\end{tabular}

Table 6 The need for change of current pest control regimen and the reasons for change

\begin{tabular}{lllllll}
\hline \multirow{2}{*}{ Response } & \multicolumn{7}{l}{ Percent response in each age group } \\
\cline { 2 - 7 } & $18-25$ & $26-30$ & $31-40$ & $41-50$ & $51-60$ & Total \\
\hline Yes & 8 & 13 & 32 & 15 & 8 & 76 \\
No & 3 & 4 & 9 & 4 & 4 & 24 \\
\hline$\chi^{2}$ value =22.15, df= & $4, \mathrm{P}<0.05$ & & & & & \\
\hline Reasons & $18-25$ & $26-30$ & $31-40$ & $41-50$ & $51-60$ & Total \\
\hline $\begin{array}{l}\text { Environmentally } \\
\text { unfriendly }\end{array}$ & 0 & 11 & 17 & 9 & 6 & 42 \\
$\begin{array}{l}\text { Adverse effect on } \\
\text { health }\end{array}$ & 5 & 4 & 16 & 7 & 4 & 35 \\
$\begin{array}{l}\text { Bean } \\
\text { Contamination }\end{array}$ & 3 & 1 & 3 & 0 & 0 & 7 \\
Bad odour & 3 & 1 & 7 & 4 & 1 & 16 \\
\hline
\end{tabular}

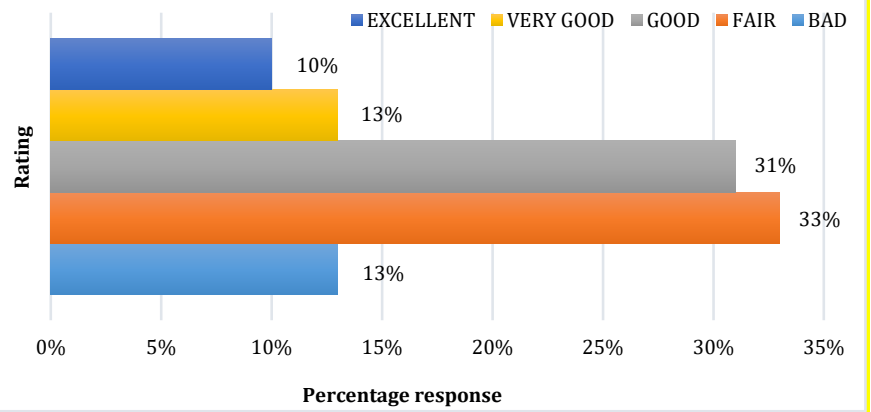

Fig. 4 Rating of control method that would use less or no pesticide https://doi.org/10.30799/jespr.164.19050201
Majority of the respondents (76\%) said the current pest control regimen left much to be desired, hence the need for a change. The respondents within 31 to 40 and 41 to 50 age brackets representing $32 \%$ and $15 \%$ respectively demanded change (Table 6 ), with reasons like adverse effect on the environment and health, bad odour and contamination of the cocoa bean. The issue of adverse effect on the environment and people featured prominently scoring $42 \%$ and $35 \%$ respectively. Introduction of an equally effective pest control regimen that will use less or no pesticide at all seemed not to be appealing to respondents, as the response of $54 \%$ of them ranged from good to excellent (Fig. 4).

\subsection{Levels of Pesticide Residues Found in Wall Surfaces of Storage Structures} and in Soils Around the Structure

Generally, there were no detectable levels of any active ingredients of stored cocoa pesticides in the soil samples taken from $5 \mathrm{~m}$ and $10 \mathrm{~m}$ away from storage structures where the various treatment regimen was imposed, except for Fogging at threshold and QCC treatments. Some level of Bifenthrin (0.025 ppm) was detected in soil sample collected $10 \mathrm{~m}$ away from the storage facility in which Fogging was done. Substantial levels of Deltamethrin, Cypermethrin, $\lambda$ Cyhalothrin and Bifenthrin were detected in soil samples taken $10 \mathrm{~m}$ away from the QCC treatment storage structure (Table 7). It was only Deltamethrin $(0.011 \mathrm{ppm})$ that was detected in soil $5 \mathrm{~m}$ away from QCC treatment storage structure.

Apart from Pyrethrin and Acetamiprid, all active ingredients were detected in paint samples taken from the walls of the various treatment facilities. The levels of these active ingredients were very high; way above their MRLs in cocoa. It is instructive to indicate that Cypermethrin that was last used in cocoa storage environment in 2015 (3 years back) was also detected in all the wall paint samples tested.

Table 7 Residues of various active ingredients in cocoa storage environments subjected to different insecticide treatments

\begin{tabular}{|c|c|c|c|c|}
\hline \multirow{2}{*}{$\begin{array}{l}\text { Treatment } \\
\text { Regimen }\end{array}$} & \multirow{2}{*}{$\begin{array}{l}\text { Active } \\
\text { ingredient }\end{array}$} & \multicolumn{3}{|c|}{ Level of residue in environment (ppm) } \\
\hline & & In soil $(5 \mathrm{~m})$ & In soil $(10 \mathrm{~m})$ & In Wall Paint \\
\hline \multirow{7}{*}{ Aeration } & Allethrin & ND & ND & 0.027 \\
\hline & Pyrethrin & ND & ND & ND \\
\hline & Deltamethrin & ND & ND & 0.100 \\
\hline & Cypermethrin & ND & ND & 0.037 \\
\hline & Acetamiprid & ND & ND & ND \\
\hline & Cyhalothrin & ND & ND & ND \\
\hline & Bifenthrin & ND & ND & 0.042 \\
\hline \multirow{7}{*}{$\begin{array}{l}\text { Pheromone } \\
\text { only }\end{array}$} & Allethrin & ND & ND & ND \\
\hline & Pyrethrin & ND & ND & ND \\
\hline & Deltamethrin & ND & ND & 0.028 \\
\hline & Cypermethrin & ND & ND & 0.072 \\
\hline & Acetamiprid & ND & ND & ND \\
\hline & Cyhalothrin & ND & ND & ND \\
\hline & Bifenthrin & ND & ND & ND \\
\hline \multirow{7}{*}{ Combined } & Allethrin & ND & ND & 0.029 \\
\hline & Pyrethrin & ND & ND & ND \\
\hline & Deltamethrin & ND & ND & 0.106 \\
\hline & Cypermethrin & ND & ND & 0.037 \\
\hline & Acetamiprid & ND & ND & ND \\
\hline & Cyhalothrin & ND & ND & ND \\
\hline & Bifenthrin & ND & ND & 0.044 \\
\hline \multirow{7}{*}{$\begin{array}{l}\text { Fogging at } \\
\text { Action } \\
\text { Threshold }\end{array}$} & Allethrin & ND & ND & 0.029 \\
\hline & Pyrethrin & ND & ND & ND \\
\hline & Deltamethrin & ND & ND & 0.106 \\
\hline & Cypermethrin & ND & ND & 0.037 \\
\hline & Acetamiprid & ND & ND & ND \\
\hline & Cyhalothrin & ND & ND & ND \\
\hline & Bifenthrin & ND & 0.025 & 0.044 \\
\hline \multirow{7}{*}{ QCC } & Allethrin & ND & ND & 0.032 \\
\hline & Pyrethrin & ND & ND & ND \\
\hline & Deltamethrin & 0.011 & 0.053 & 0.621 \\
\hline & Cypermethrin & ND & 0.046 & 0.518 \\
\hline & Acetamiprid & ND & ND & ND \\
\hline & Cyhalothrin & ND & 0.034 & 0.044 \\
\hline & Bifenthrin & ND & 0.105 & 0.272 \\
\hline
\end{tabular}

MRLs: Allethrin $=0.01$ ppm; Pyrethrin $=1$ ppm; Deltamethrin $=0.05$ ppm; Cypermethrin $=0.02$ ppm; Acetamiprid $=0.02$ ppm; Cyhalothrin $=0.01$ ppm; Bifenthrin $=0.1 \mathrm{ppm}$

Postharvest handling of cocoa in Ghana is carried out by people of all ages. However, this aspect of cocoa value chain is deemed to be for the energetic educated class. In this study, the age of respondents ranged 18 
to 60 years with the average age being 36 years. This compares with the finding of Saed and others [16], who reported mean age of the participants in a study on Knowledge and practices of pesticide use among farm workers in the West Bank, Palestine: safety implications in West bank, Palestine as 39 years.

In studies on pesticide knowledge, perception and practices by agricultural pesticide users and residents around their farms conducted by Saed and others [16] and Pasiana [17], 97.9 and $99.7 \%$ respectively of the subjects were males indicating that pesticide application is a male dominated pursuit. The findings of this study also support this assertion since as many as $77 \%$ of the respondents were males.

Almost all the respondents in this study had formal education (98\%) with $71 \%$ having had secondary or tertiary education. This may be due to the fact that purchasing of cocoa, it's warehousing and pest control require appreciable level of education as it entails safe handling and use of pesticides. According to Gaber and Hassan Abdel-Latif [18], low level of education leads to lack of appreciation of health effects of pesticide use and the converse holds. Good knowledge on safety in pesticide use is significantly influenced by educational level of farm workers [19].

The current pesticide application regimen in the cocoa storage environment is a calendar based prophylactic treatment that has existed for over fifteen years. It is an effective regimen in terms of preserving the quality of cocoa beans. Standard procedures like frequency, time of application and volume or quantity of pesticide to use were generally followed with a little violation. This study revealed that while fogging was carried out three times a week and spraying inside storage facilities only once at the beginning of the season, as an industry policy, there were deviations where fogging was carried out four times, twice or once a week while spraying was undertaken more than once in a season. Application of lower frequencies than that set by the industry was attributed to lack of logistics like vehicles to go around the various facilities. On the other hand, higher application frequencies were undertaken to meet revenue targets for various districts.

Respondents, especially applicators, were aware of health effects of pesticides and hence knew the importance of the use of Personal Protective Equipment/Devices (PPE/PPDs) during pesticide application mainly due to their level of education. This finding supports the report of earlier studies that showed a significant relation between farmers' educational level and their level of knowledge in pesticide use [20,21]. About a third of applicators were however, observed not using the full complement of the PPE with the excuse that they feel uncomfortable in PPE when working in hot weather.

The fact that some of the teams were as large as 15 people means a large number of applicators could be contaminated during the pesticide handling and use during operations, as many of them would be without the full complement of PPE. Similar study by [17] showed that in spite of high awareness in harmful effects of pesticides many farmers still use PPDs in an inappropriate manner, or not at all, during pesticide handling, mainly due to ignorance or probably due to lack of effective communication of these risks by government authorities and technical advisors. On the other hand, [18] reported that high level of education may not necessarily be a motivating factor for the practice of safety measures while applying pesticides.

This study also revealed that pesticide applicators (QCC disinfestation staff) experience headache, sneezing, sweating, numbness of fingers, tiredness and runny nose after application of pesticide especially when not fully protected. The most frequent self-reported toxicity symptoms associated with pesticide use in this study, are similar to those reported by [16]. Warehouse operators and residents close to warehouses were hardly informed of pending pesticide application and hence were not able to adequately plan to prevent contaminations and thus suffer these toxicity symptoms. The general desire of respondents of this study was the need for a change in the current pest control regimen for the following reasons; adverse effect on the environment (environmentally unfriendly), adverse health effect on people, contamination of cocoa bean and bad odour of pesticides.

The finding from this study showed that apart from Pyrethrin and Acetamiprid all other active ingredients in insecticides used in controlling pests in the cocoa storage environment remained in the wall paint of storage facilities and in the soil around the storage structures. This is a worrying situation since workers in such facilities often hang their clothes on wall, lean against the wall, touch the walls with their hands, sit on bare ground exposing themselves to these serious sources of contamination. It is also a major source of worry as in the long run, these active ingredients in the soil would reach underground and surface waters through leaching and run offs.

\section{Conclusion}

The result of this study indicates that in spite of the high educational background of those who work in the cocoa storage environment, there is lack of proper adherence to pest control procedures, especially dissemination of information concerning upcoming pest control operation, wearing of full complement of PPE, frequency of spraying and fogging leading to contamination of operators, residents and the environment.

\section{Acknowledgement}

We wish to express my sincere gratitude to Ghana Cocoa Board for allowing this research to be conducted using their workforce, Laboratory and storage environment.

\section{References}

[1] P. Okori, P.R. Rubaihayo, E. Adipala, J. Fahlesion, C. Dixelium, Population studies of fungi of plant pathogen; perspectives for control with specific reference to grey leaf spot, Afr. Crop Sci. J. 12(4) (2004) 243-249.

[2] D.W. Ogendo, B.H. Hagstrum, Alternatives to pesticide in stored products IPM, Kluwer Academic Publishers, Norwell, Massachusetts, 2004.

[3] FAO/UNEP/WHO, Childhood pesticide poisoning: information for advocacy and action, United Nations Environment Program, Geneva, 2004

[4] WHO, The impact of pesticides on health: preventing intentional and unintentional deaths from pesticide poisoning, World Health Organization, Geneva, 2004.

[5] L. Goldman, N. Tran, Toxics and poverty: the impact of toxic substances on the poor in developing countries, World Bank, Washington DC, 2002.

[6] L. Goldman, Childhood pesticide poisoning: Information for advocacy and action, Chemicals Program of the United Nations Environment, Geneva, 2004.

[7] S.A. Mansour, Pesticide exposure- Egyptian scene, Toxicol. 198 (2004) 91-115.

[8] M. Sanborn, K.J. Kerr, L.H. Sanin, D.C. Cole, K.L. Bassil, C. Vakil, Non-cancer health effects of pesticides: systematic review and implications for family doctors, Canad. Family Phys. 53(10) (2007) 1712-1720.

[9] J. Jurewicz, W. Hanke, Prenatal and childhood exposure to pesticides and neurobehavioral development: review of epidemiological studies, Int. J. Occup. Med. Environ. Health 21(2) (2008) 121-132.

[10] F.P. Carvalho, F. Gonzalez-Farias, J.P. Villeneuve, C. Cattini, M. HernandezGarza, et al., Distribution, fate and effects of pesticide residues in tropical coastal lagoons of the Northwest of Mexico, Environ. Technol. 23 (2002) 12571270 .

[11] F.P. Carvalho, S. Montenegro-Guillen, J. Villeneuve, P. Cattini, C. Tolosa, et al., Toxaphene residues from cotton fields in soils and in the coastal environment of Nicaragua, Chemosphere 53 (2003) 627-636.

[12] M.E. Harnley, A. Bradman, M. Nishioka, T.E. McKone, D. Smith, et al., Pesticides in dust from homes in agricultural area, Environ. Sci. Technol. 43 (2009) 8767 8774.

[13] L.P. Naeher, N.S. Tulve, P.P. Egeghy, D.B. Barr, O. Adetona, et al., Organophosphorus and pyrethroid insecticide urinary metabolite concentrations in young children living in a southeastern United States city, Sci. Total Environ. 408 (2010) 1145-1153.

[14] J. Zhu, C. Ryne, R. Unelius, P.G. Valeur, C. Lofstedt, Re-identification of the female sex pheromone of the Indian meal moth, P. interpunctella: evidence for a fourcomponent pheromone blend, Entomol. Exp. App. 85 (1999) 137-146

[15] J. Fillion, Analytical methods for residual compositional substances of agricultural chemicals, Feed Addit. Veter. Drugs Food 2000 (2005) 0124001.

[16] H.Z. Saed, Ansam, F.S. Waleed, M.S. Rahmat, A. Suleiman, et al., Knowledge and practices of pesticide use among farm workers in the West Bank, Palestine: safety implications, Environ. Health Prevent. Med. 15(4) (2010) 252-261.

[17] J.O. Pasiani, P. Torres, J.R. Silva, B.Z. Diniz, E.D. Caldas, Knowledge, attitudes, practices and biomonitoring of farmers and residents exposed to pesticides in Brazil, Int. J. Environ. Res. Public Health 9 (2012) 3051-3068.

[18] S. Gaber, S.H. Abdel-Latif, Effect of education and health locus of control on safe use of pesticides: a cross sectional random study, J. Occup. Med. Toxicol. 7 (2012) 3-ENDPAGE.

[19] P.K. Lavanya, K.R. Giridhar, Knowledge and practices of safety use of pesticides among farm workers, IOSR J. Agri. Veter. Sci. 6 (2) (2013) 2319-2372.

[20] M.M. Yassin, T.A. Abu-Mourad, J.M. Safi, Knowledge, attitude, practice, and toxicity symptoms associated with pesticide use among farm workers in the Gaza Strip, Occup. Environ. Med. 59 (2002) 387-394.

[21] M.R. Nazaril, H.J. Bin, S. Hassan, The role of television in the enhancement of farmers' agricultural knowledge, Afr. J. Appl. Res.6 (2011) 931-936. 